\title{
Analysis of errors in the discrimination learning of normal and retarded children'
}

ALFRED A. BAUMEISTER

UNIVERSITY OF ALABAMA

Normal and mentally retarded children were tested on a three-choice size discrimination leaming problem. Most of the normals and about half of the retardates were able to reach a criterion of five consecutive correct responses within 60 trials. An analysis of response patterns indicated that the nonlearners made a much higher proportion of perseverative errors than the learners. By contrast, the successful Ss were characterized by a pronounced tendency to commit altemation errors.

The discrimination learning abilities of mentally retarded Ss have been investigated in a variety of contexts. One of the most consistent findings is that retardates are extremely heterogeneous performers. Typically it is reported that some of these individuals learn discriminations rapidly and others, with a similar psychometric status, have great difficulty.

The present experiment was conducted to analyze the response patterns which characterize retarded and normal individuals' interactions with the task. Usually, choice behavior in a discrimination learning trial is regarded as correct or incorrect. Actually, the latter designation, as Harlow (1959) demonstrated, conceals a considerable variety of meaningful stimulus-response contingencies.

Subjects

The Ss were 30 adolescent retardates selected from a residential institution and 20 normal children. Four retardates and two normals were excluded from the study for failure to understand the instructions.

The means of IQs (Stanford-Binet) and CAs of the retarded group were 60.1 and $14.7 \mathrm{yrs}$. The corresponding standard deviations were 9.5 and $1.5 \mathrm{yrs}$. The normals had a mean IQ (PPVT) of 107.2 with a standard deviation of 15.0. Their average CA was 7.9 yrs. with a standard deviation of 1.6 yrs.

\section{Procedure}

The task was a three-choice size discrimination learning problem. On each trial $S$ was shown three white, square, $3 / 4$ in. thick blocks with an area ratio of $2: 1$. The areas of the blocks were 1,2 , and 4 sq. in. $M \& M$ candies were used for reinforcements in a noncorrection procedure. The stimuli were presented on a retractable tray and a screen was lowered between trials while E rearranged the blocks. Positions were varied from trial to trial in a prearranged random order. The criterion of learning was five consecutive correct responses. If $\mathrm{S}$ had not achieved criterion by 60 triels, training was discontinued and $\mathrm{S}$ classified as a "nonlearner."
Resulis

The discrimination task appeared to be somewhat more difficult $(p<.05)$ for the retarded group. Fourteen of these Ss achieved the criterion of learning, while 12 failed to do so. By contrast, only three of the 18 normal children were unable to learn the discrimination. The retardates who met the definition of learning did so in about the same mean number of trials as the normal learners (21 trials vs, 27 trials). The unsuccessful Ss were found to be slightly, but not significantly, lower in MA.

\section{Analyses of errors}

Errors were classified into five basic types: Differential Cue, Stimulus Perseveration, Position Habit, + Response Shift, and - Response Shift. Although these terms are conceptually similar to those used by Harlow (1959) and others, the definitions are, in some cases, markedly different. It is necessary, therefore, to briefly describe each of the error factors observed in the present study. (a) Differential Cue (DC) errors were attributed to the ambiguity between rewarded object and rewarded position. A DC error was recorded when $S$ erroneously responded to the same position which had been occupied by the rewarded object on the immediately preceding trial. (b) Position Habit (PH) errors were defined as tendencies to respond consistently to the same position. PH errors were scored from the second consecutive incorrect response to a particular position. Although they were made operationally distinct from $D C$ errors, it is possible that these two types of error factors are products of similar contingencies. (c) Stimulus Perseveration (SP) errors were attributed to S's stimulus preferences. Such errors occurred on trials in which $\mathrm{S}$ chose the same nonrewarded object as he had on the immediately previous trial. (d) + Response Shift (+RS) errors reflected a tendency to alternate from a rewarded object to an incorrect object in another position. (e) - Response Shift (-RS) errors represented a shift from an incorrect block to the other nonrewarded object.

The results of the error analyses are graphically displayed in Fig. 1. Data are not presented for the normal nonlearners because there were only three Ss in this category.

It may be seen that percentages of the various types of errors were virtually identical for the two groups of learners, whether normal or mentally retarded. On the other hand, the retardates who failed to achieve the criterion of learning displayed markedly different patterns of responses. Their errors tended to be a 


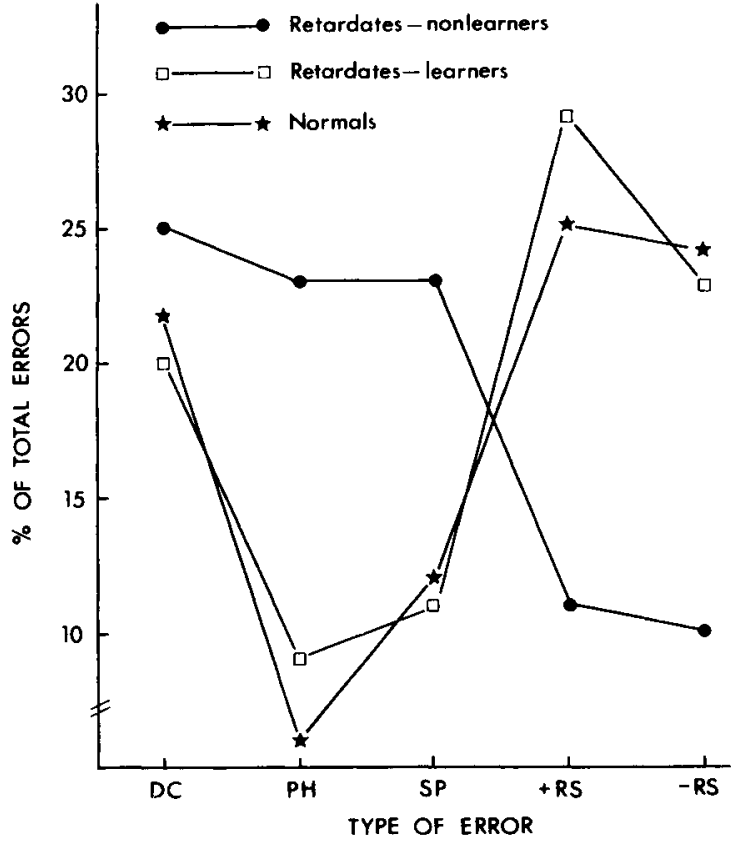

Fig. 1. Percentages of the various types of errors for each group.

perseverative nature-either Position Habitor Stimulus Perseveration. The responses of the successful Ss were characterized more by alternation tendencies, i.e., response shift errors. The three groups yielded about the same percentage of Differential Cue errors. These observations were confirmed by analyses of variance applied to the percentages.

\section{Discussion}

These results strongly indicate that different types of errors underlie the performance of learners and nonlearners. In some learning situations it may be important to make the right kind of errors. In this connection, the response pattern of mental defectives who learned the size discrimination could not be distinguished from that of the normal group.

Although a developmental change from perseveration to alternation has been noted (Weir, 1964), the mechanisms which control these tendencies are not immediately clear. Possibly the Position Habit error is maintained because $S$ does receive some objective reinforcement (candy + interaction with $\mathrm{E}$ ) for responding to position. Under the procedure employed in the present study, he would be under a VR schedule with an average value of $1: 3$. For some retarded individuals with a history of erratic and intermittent reinforcement, this may be a good schedule for maintaining behavior.

The tendency to commit Stimulus Perseveration errors is not as easily rationalized, for the reason that the controlling contingencies are difficult to specify. Certainly, the $\mathrm{S}$ who persistently responds to the same "incorrect" stimulus block from one trial to the next never receives the objective reward. Moreover, this response pattern obviously requires that the subject discriminate the stimuli on the basis of size.

The effective learners were those who alternated their responses. In fact, they frequently shifted from the "correct" cue (+RS error). It is clear that this reaction tendency was the one most likely to lead to the discovery that size was the relevant dimension. Perhaps, during the initial stages of learning, these subjects employed the strategy that a response to a particular stimulus would, on the subsequent trial, have a reduced probability of being rewarded. Such a set might be particularly strong for those children who perceived the "game" as a guessing contest with E.

The most extensive analysis of the error factors which operate in the discrimination learning of mental defectives was conducted by Ellis, Girardeau, \& Pryer (1962). They reported that retardates tended to commit Position Habit errors more persistently than a normal comparison group. On the other hand, normals were found to make a higher proportion of Stimulus Perseveration errors. House \& Zeaman (1963) have also reported that the proportion of position errors is inversely related to mental age.

\section{References}

Ellis, N . R., Girardeau, F. L., \& Pryer, M. W. Analysis of learning sets in normal and severely defective humans. J. comp. physiol. Psychol., 1962, 55, 860-865.

Harlow, H. F. Learning set and error factor theory. In S. Koch (Ed.), Psychology: A study of a science. Vol. 2. New York: McGrawHill, 1959. Pp. 492-537.

House, B. J., \& Zeaman, D. Miniature experiments in the discrimination learning of retardates. In L. P. Lipsitt \& C. C. Spiker (Eds.), Advances in child development and behavior. Vol. 1. New York: Academic Press, 1963. Pp. 313-374.

Weir, M. W. Developmental changes in problem-solving strategies. Psychol. Rev., 1964, 71, 473-490

Note

1. Supported, in part, by PHS Grant R01 HD 02588-01. 